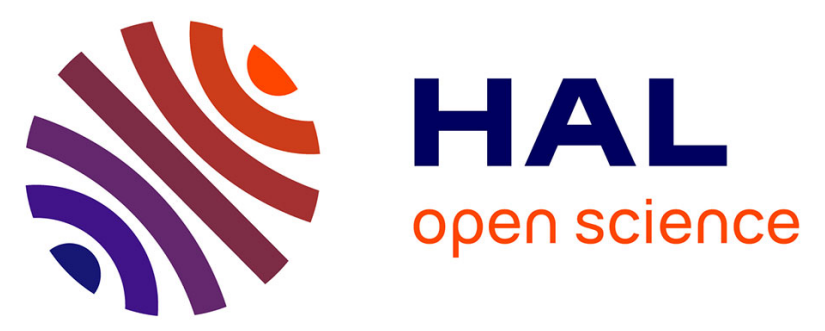

\title{
Dearomatization of a 3-Hydroxypyridine through an unexpected Oxidative Deformylation Process: an Entry to Aza-cyclohexadienones
}

\author{
Afef Mabrouki, Patricia Le Nahenec-Martel, Abdelkader Kriaa, Ahmed \\ Hedhli, Pierre-Yves Renard, Cyrille Sabot
}

\section{To cite this version:}

Afef Mabrouki, Patricia Le Nahenec-Martel, Abdelkader Kriaa, Ahmed Hedhli, Pierre-Yves Renard, et al.. Dearomatization of a 3-Hydroxypyridine through an unexpected Oxidative Deformylation Process: an Entry to Aza-cyclohexadienones. SYNLETT, 2020, 31 (15), pp.1497-1500. 10.1055/s0040-1706870 . hal-03010593

HAL Id: hal-03010593

https://hal-normandie-univ.archives-ouvertes.fr/hal-03010593

Submitted on 2 Dec 2020

HAL is a multi-disciplinary open access archive for the deposit and dissemination of scientific research documents, whether they are published or not. The documents may come from teaching and research institutions in France or abroad, or from public or private research centers.
L'archive ouverte pluridisciplinaire HAL, est destinée au dépôt et à la diffusion de documents scientifiques de niveau recherche, publiés ou non, émanant des établissements d'enseignement et de recherche français ou étrangers, des laboratoires publics ou privés. 


\section{Dearomatization of a 3-Hydroxypyridine through an unexpected Oxidative Deformylation Process: an Entry to Aza-cyclohexadienones}

\author{
Afef Mabrouki ${ }^{\mathrm{a}}$ \\ Patricia Le Nahenec-Martel ${ }^{b}$ \\ Abdelkader Kriaaa \\ Ahmed Hedhlia \\ Pierre-Yves Renard ${ }^{\mathrm{b}}$ \\ Cyrille Sabot*b \\ a Laboratory of Molecular Organic Chemistry, National Higher \\ Engineering School of Tunis, 5 avenue Taha Hussein, \\ Montfleury, 1089, Tunis, Tunisia \\ ${ }^{\mathrm{b}}$ Normandie Univ, CNRS, UNIROUEN, INSA Rouen, COBRA \\ (UMR 6014), 76000 Rouen, France \\ Cyrille.sabot@univ-rouen.fr \\ Click here to insert a dedication
}

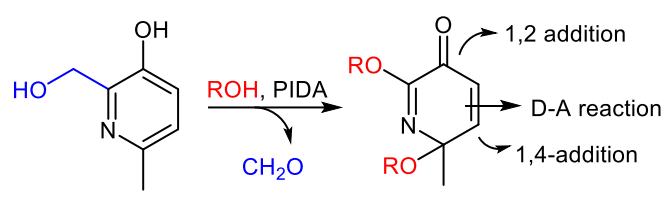

Although the oxidative homocoupling of 3-hydroxypyridines was recently described, ${ }^{20}$ the competitive oxidation of the pyridine nitrogen and hydroxyl group is a plausible issue ${ }^{21}$ which may have prevented further dearomatization studies and reports on hydroxypyridine systems.

Herein, as a-proof-of-concept study, we report the unexpected formation of a 5-aza-2,5-cyclohexadien-1-one via an oxidative deformylation/1,3-alkoxy rearrangement process of commercially available 2,6-lutidine- $\alpha 2,3$-diol. The chemical reactivity of the corresponding unreported dearomatized product was investigated.

Hypervalent iodine reagents, such as phenyliodine(III) diacetate (PIDA) $\mathrm{PhI}(\mathrm{OAc})_{2}$, are reagents of choice to promote phenols oxidation under mild and environmentally friendly conditions. ${ }^{22-27}$ Accordingly, the oxidation of commercially available 2,6-lutidine- $\alpha 2,3$-diol $\mathbf{1}$ was investigated under standard alcoholic conditions with the aim to provide the corresponding aza- $p$-quinol ether 3 . To this end, the oxidation was carried out in the presence of 1 equivalent of PIDA in $\mathrm{MeOH}$ at room temperature for 15 minutes (Scheme 2). dienone-phenol rearrangements, 6,9 to cite a few (Scheme $1, \mathrm{X}=$ $\mathrm{CH})$.

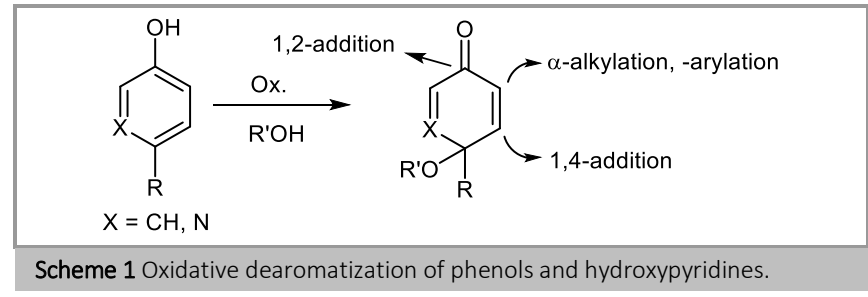

Whilst this strategy has extensively been studied and exploited through the expedient synthesis of natural products, ${ }^{10-14}$ on the other hand the oxidative dearomatization of their hydroxypyridine counterparts has not been reported yet, despite promising synthesis applications (Scheme 1, X = N).15-19

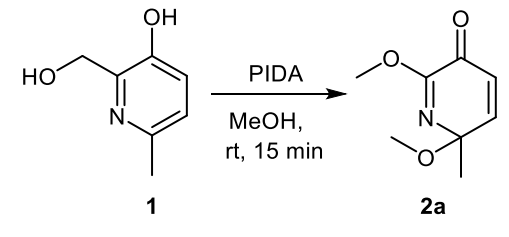<smiles>COC1(C)C=CC(=O)C(CO)=N1</smiles>

With: a) PIDA (1 equiv.):

b) PIDA (2 equiv.)

$27 \%$

$60 \%$

Scheme 2 Oxidative hydroxypyridine dearomatization

Surprisingly, the expected aza-p-quinol ether 3 was not formed, but instead, compound $2 \mathrm{a}$ along with unreacted starting hydroxypyridine 1 in a 2:3 ratio was observed by ${ }^{1} \mathrm{H}$ NMR analysis of the crude reaction mixture. Purification of the crude 
mixture using flash column chromatography provided compound 2a in 27\% yield, whose structure was confirmed by spectroscopic and spectrometric data. Unexpectedly, the hydroxy-methyl group in $\mathbf{1}$ was replaced by a methoxy substitutent in $\mathbf{2 a}$. Compound $\mathbf{2 a}$ being two oxidation states higher than the parent compound $\mathbf{1}$, 2.14 equivalents of PIDA were used in order to drive the reaction to completion and improve the overall efficiency of this transformation. As expected, under these optimized conditions, compound 2a was isolated in $60 \%$ yield (Scheme $2 \mathrm{~b}$ ).

Following these preliminary results, the reaction was conducted in other low-boiling-point alcoholic solvents, and obtained results are presented in Table 1.28

Table 1 Solvent-scope of the reaction<smiles>[R]OC1=NC([R9])(C)C=CC1=O</smiles>

2

\begin{tabular}{lllll}
\hline Entry & Solvent & $\mathrm{R}$ & Cmpds & Yield (\%) \\
\hline 1 & $\mathrm{MeOH}$ & $\mathrm{Me}$ & $2 \mathrm{a}$ & 60 \\
2 & $\mathrm{EtOH}$ & $\mathrm{Et}$ & $2 \mathrm{~b}$ & 43 \\
3 & $i \mathrm{PrOH}$ & $i \mathrm{Pr}$ & $2 \mathrm{c}$ & traces \\
4 & TFE & $\mathrm{CF}_{2} \mathrm{CH}_{2}$ & $2 \mathrm{~d}$ & 11 \\
5 & $\mathrm{HFIP}$ & $\left(\mathrm{CF}_{3}\right)_{2} \mathrm{CH}$ & $2 \mathrm{e}$ & - \\
\hline
\end{tabular}

${ }^{a}$ Reaction conditions: PIDA (2.14 equiv.), solvent, rt, $15 \mathrm{~min}$.

The yields of dearomatized 3-hydroxypyridines decreased as the bulkiness of the solvent increased. In fact, a moderate yield of $43 \%$ of $\mathbf{2 b}$ was obtained in ethanol (entry 2 ), whereas only traces of product 2c could be identified in isopropanol (entry 3). Besides, the use of electron-deficient alcohols such as 2,2,2trifluoroethanol (TFE) markedly decreased the efficiency of the transformation with the isolation of $11 \%$ of dearomatized compound $\mathbf{2 d}$, while product $\mathbf{2 b}$ was obtained in $43 \%$ in nonfluorinated analog, ethanol (entry 2versus 4). Not surprisingly, no product was isolated when the reaction was conducted in 1,1,1,3,3,3-hexa-fluoroisopropanol (HFIP), a bulky and nonnucleophilic fluorinated alcohol. The reaction was also explored in the non-protic and chemically inert solvent, dichloromethane, in order to investigate whether the acetic acid released in the course of the reaction could trap the oxidized intermediates as alcoholic solvents did (Scheme 3).

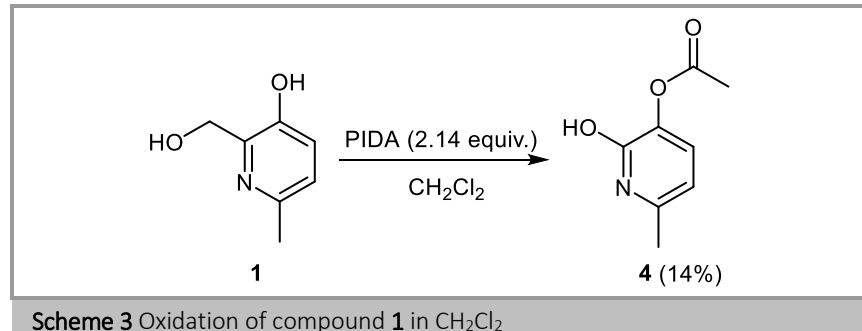

Under these conditions, only the deformylated mono-oxidized compound 4 was obtained, albeit in a low $14 \%$ yield. In contrast to alcoholic solvents, the formation of this compound would involve a mono-oxidation process.
No example of such unfused aza-p-quinol ether systems having being reported yet, their reactivity was investigated using the representative compound 2a. First, the direct reductive aromatization of $\mathbf{2 a}$ to provide an electron-rich pyridine, was carried out by the action of $\mathrm{Pd} / \mathrm{C}$ mediated hydrogenation, which delivered compound $\mathbf{5}$ in a low $37 \%$ yield. This volatile material possessed a pleasant fragrance (Scheme 4).<smiles>COC1=NC(C)(OC)C=CC1=O</smiles>

Scheme 4 Direct aromatization of aza-p-quinol ether $2 a$

Then, compound 2a was subject to 1,2-nucleophilic addition conditions. In view of the operational simplicity associated with the use of non toxic allyl indium reagents, compound $\mathbf{2 a}$ was treated with indium (In) in the presence of allyl bromide to produce the corresponding allylic alcohol 6 in $46 \%$ yield as a mixture of inseparable diastereoisomers in a 1:1 ratio (Scheme $5)$.

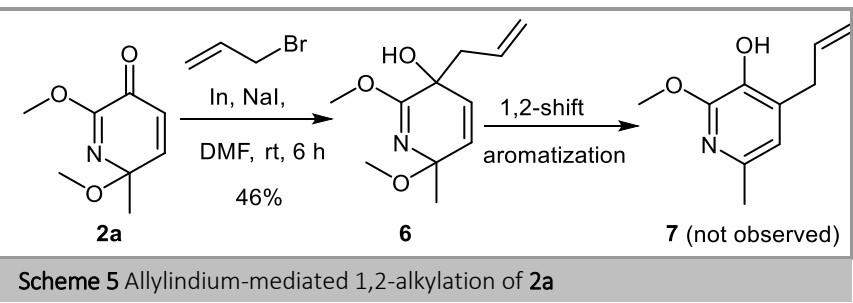

It is worth mentioning that, in contrast to what was reported with $p$-quinol ether systems, ${ }^{29}$ no further anionic vinylogous semipinacol type rearrangement of $\mathbf{6}$ into $\mathbf{7}$ was observed in the present case.

The conjugate addition of in situ generated organocuprate reagent to the $\alpha, \beta$-unsaturated system of $2 \mathbf{a}$ was not observed (Scheme 6a). In fact, the reaction of methyl magnesium bromide in the presence of copper (I) bromide favored the formation of carbonyl addition product $\mathbf{8}$, which was isolated in 33\% yield as a $\sim 3: 1$ mixture of inseparable isomers.

a)

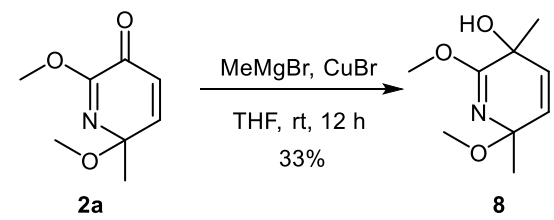

b)

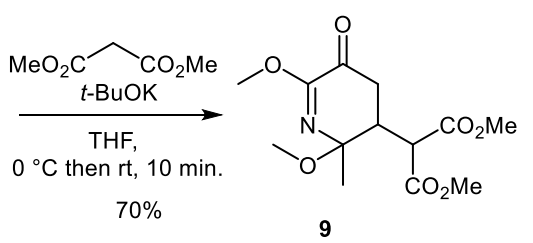

Scheme 6 Investigation of conjugate additions with dimethyl malonate

Thus, the reaction was next investigated with the Michael donor dimethyl malonate, which enabled this time the formation 
of the 1,4-addition product $\mathbf{9}$, isolated in $70 \%$ yield as a single diastereoisomer (Scheme 6b).

Next, the reactivity of aza- $p$-quinol ether as a diene in a DielsAlder reaction was investigated. To this end, compound 2a was reacted with freshly distilled cyclopentadiene in the presence of phosphoric acid as the catalyst (Scheme 7). ${ }^{30}$ The corresponding cycloadduct 10 was formed in $23 \%$ isolated yield. This low yield may partly be ascribed to the formation of fused bicyclic pyridine 11, which can be formed cleanly in $77 \%$ yield from isolated compound 10, in the presence of methanesulfonic acid in methanol.

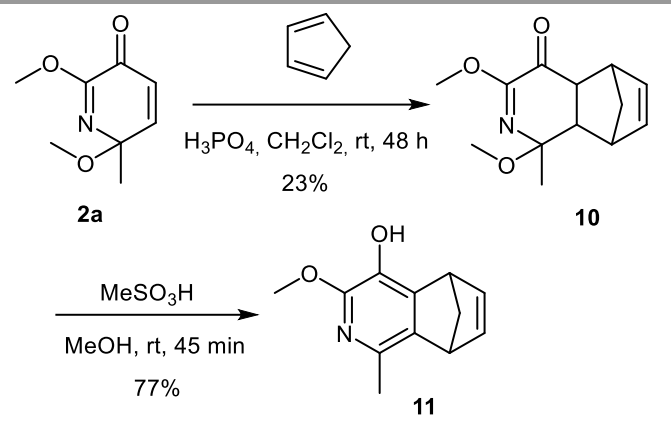

Scheme 7 Diels-Alder reaction of aza- $p$-quinol ether $2 a$

Finally, a plausible reaction mechanism for the oxidative deformylation process of 3-hydroxypyridine $\mathbf{1}$ can be proposed in Scheme 8. The oxidation of the aromatic hydroxyl function promoted by the first equivalent of hypervalent iodine reagent would lead to the formation of the phenoxonium intermediate 12, which would subsequently be trapped by methanol to furnish the transient intermediate $\mathbf{1 3}$.

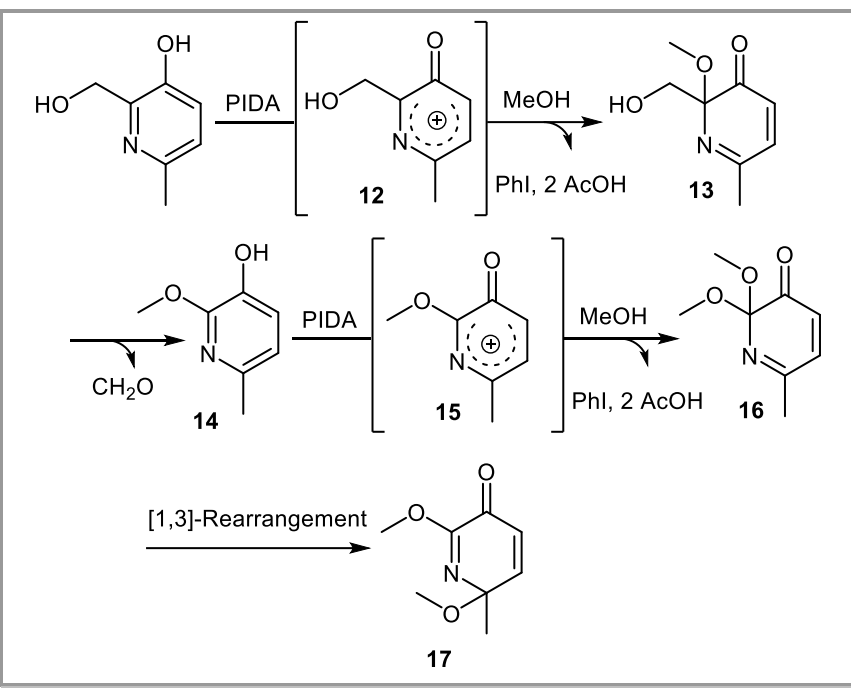

Scheme 8 Proposed reaction mechanism

Then, compound 13 would undergo a retroaldolizationdriven aromatization process to provide the 2-methoxy-3hydroxy-pyridine 14. This reaction would occur with the concomitant release of formaldehyde. It is worth noting that the putative intermediate $\mathbf{1 4}$ has not been isolated, even in the presence of sub-stoichiometric amounts of PIDA, presumably because this electron-rich pyridine is more readily oxidized than the starting 3-hydroxypyridine $\mathbf{1}$. Then, the second equivalent of PIDA would oxidize 14 to generate the aza-o-quinone monoketal
16 through the regioselective addition of methanol to the methoxy-stabilized carbocation at the $\alpha$-position of the carbonyl of the intermediate 15. ${ }^{31}$ This compound would be converted into enone 17 through a 1,3-methoxy rearrangement process, similarly to what was reported with $o$-quinone monoketals under Lewis acid catalysis. ${ }^{32}$ Accordingly, the presence of the temporary hydroxy-methyl group at the position 2 of the pyridine ring system of $\mathbf{1}$ would play an important role in favoring the methanol addition to occur at this position due to the enhanced stability of this tertiary carbocation. To investigate this point, the 3-hydroxypyridine 18, unsubstituted at position 2, was oxidized under identical optimized PIDA conditions (Scheme 9).

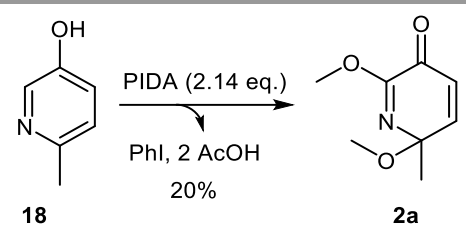

Scheme 9 Oxidation of 2-unsubstituted-3-hydroxypyridine 18

This reaction provided 2a in only $20 \%$ yield, instead of $60 \%$ when the position 2 was functionalized by the hydroxy-methyl substituent. This result shows that the presence of a removable hydroxy-methyl group, was required to ensure effective formation of aza-p-quinol ethers 2.

In conclusion, the first oxidative dearomatization of a hydroxypyridine system leading to the formation of aza- $p$-quinol ethers, is reported. This reaction proceeded under mild conditions, and involved a deformylation/1,3-migration process favoring the formation of aza- $p$-quinol ethers. Subsequent modifications of this particular cyclohexadienone through 1,2- , 1,4-addition, and Diels-Alder reaction were investigated.

\section{Funding Information}

This work was funded by the Centre National de la Recherche Scientifique (CNRS), INSA Rouen, Normandie Rouen University, Région Normandie and the Labex SynOrg (ANR-11-LABX-0029).

\section{Acknowledgment}

We thank Albert Marcual (CNRS) for HRMS analyses.

\section{Supporting Information}

YES (this text will be updated with links prior to publication)

\section{Primary Data}

NO (this text will be deleted prior to publication)

\section{References and Notes}

(1) Magdziak, D.; Meek, S. J.; Pettus, T. R. Chem. Rev. 2004, 104, 1383430.

(2) Quideau, S.; Pouységu, L.; Peixoto, P. A.; Deffieux, D., Phenol Dearomatization with Hypervalent Iodine Reagents. In Hypervalent Iodine Chemistry, Wirth, T., Ed. Springer International Publishing: Cham, 2016; pp 25-74.

(3) Signo, K.; Mammasse, Z.; Canesi, S. J. Org. Chem. 2020, 85, $2832-$ 2837.

(4) Moon, N. G.; Harned, A. M. Org. Biomol. Chem. 2017, 15, 1876-1888.

(5) Liu, Q.; Rovis, T. J. Am. Chem. Soc. 2006, 128, 2552-3. 
(6) Sawama, Y.; Masuda, M.; Nakatani, R.; Yokoyama, H.; Monguchi, Y.; Dohi, T.; Kita, Y.; Sajiki, H. Adv. Synth. Catal. 2016, 358, 3683-3687.

(7) Ohkata, K.; Tamura, Y.; Shetuni, B. B.; Takagi, R.; Miyanaga, W.; Kojima, S.; Paquette, L. A. J. Am. Chem. Soc. 2004, 126, 16783-92.

(8) Trân-Huu-Dâu, M.-E.; Wartchow, R.; Winterfeldt, E.; Wong, Y.-S. Chem. Eur. J. 2001, 7, 2349-2369.

(9) G. Taveras, A. Tetrahedron Lett. 1988, 29, 1103-1106.

(10) Moon, N. G.; Harned, A. M. Org. Lett. 2015, 17, 2218-21.

(11) L'Homme, C.; Menard, M. A.; Canesi, S. J. Org. Chem. 2014, 79, 8481 5.

(12) Jacquemot, G.; Maertens, G.; Canesi, S. Chem. Eur. J. 2015, 21, 77135.

(13) Maertens, G.; Canesi, S. Chem. Eur. J. 2016, 22, 7090-7093.

(14) Maertens, G.; Deruer, E.; Denis, M.; Canesi, S. J. Org. Chem. 2020, 85, 6098-6108.

(15) Lipshutz, B. H.; Amorelli, B. J. Am. Chem. Soc. 2009, 131, 1396-7.

(16) Lee, D.; Kondo, H.; Kuwayama, Y.; Takahashi, K.; Arima, S.; Omura, S.; Ohtawa, M.; Nagamitsu, T. Tetrahedron 2019, 75, 3178-3185.

(17) Jouanno, L. A.; Tognetti, V.; Joubert, L.; Sabot, C.; Renard, P. Y. Org. Lett. 2013, 15, 2530-3.

(18) Sabot, C.; Oueis, E.; Brune, X.; Renard, P. Y. Chem. Commun. 2012, 48, 768-70.

(19) Jouanno, L. A.; Di Mascio, V.; Tognetti, V.; Joubert, L.; Sabot, C.; Renard, P. Y. J. Org. Chem. 2014, 79, 1303-19.

(20) Yang, P. S.; Tsai, M. T.; Tsai, M. H.; Ong, C. W. Chem. Asian J. 2015 10, 849-52.

(21) Andrews, I. P.; Lewis, N. J.; McKillop, A.; Wells, A. S. Heterocycles, 1996, 43, 1151-1158.

(22) Pouységu, L.; Deffieux, D.; Quideau, S. Tetrahedron 2010, 66, 22352261.

(23) Wenderski, T. A.; Hoarau, C.; Mejorado, L.; Pettus, T. R. Tetrahedron 2010, 66, 5873-5883.
(24) Traoré, M.; Ahmed-Ali, S.; Peuchmaur, M.; Wong, Y.-S. Tetrahedron 2010, 66, 5863-5872.

(25) Guérard, K. C.; Sabot, C.; Beaulieu, M.-A.; Giroux, M.-A.; Canesi, S. Tetrahedron 2010, 66, 5893-5901.

(26) Liang, H.; Ciufolini, M. A. Tetrahedron 2010, 66, 5884-5892.

(27) Tamura, Y.; Yakura, T.; Haruta, J.; Kita, Y. J. Org. Chem. 1987, 52, 3927-3930.

(28) Aza-p-quinol ether (2a) Typical procedure

To a stirred solution of 2,6-lutidine- $\alpha 2,3$-diol (100 mg, 0.719 $\mathrm{mmol}$ ) in $1.5 \mathrm{ml}$ of solvent ( $\mathrm{MeOH}, \mathrm{EtOH}$ or TFE), phenyliodine(III) diacetate (PIDA) $\mathrm{PhI}(\mathrm{OAc}) 2$ (500 mg, $1.538 \mathrm{mmol}, 2.14$ equiv) in $1,5 \mathrm{ml}$ of solvent (MeOH, EtOH or TFE) was added dropwise (using pipette) under air atmosphere at room temperature. After stirring for $15 \mathrm{~min}$, the reaction which came yellow and was completed by TLC analysis, was concentrated under reduced pressure. The crude product was purified by flash-column chromatography on silica gel using cyclohexane and ethyl acetate $(7: 3)$ as eluent to give a yellow oil product (73 mg, $60 \%$ ).

${ }^{1} \mathrm{H} \mathrm{NMR}\left(300 \mathrm{MHz}, \mathrm{CDCl}_{3}\right) \delta(\mathrm{ppm})=7.34(\mathrm{~d}, J=10.30 \mathrm{~Hz}, 1 \mathrm{H}), 6.44$ (d, $J=10.12 \mathrm{~Hz}, 1 \mathrm{H}), 3.87(\mathrm{~s}, 3 \mathrm{H}), 3.21(\mathrm{~s}, 3 \mathrm{H}), 1.55(\mathrm{~s}, 3 \mathrm{H}) .{ }^{13} \mathrm{C} \mathrm{NMR}$ $\left(75 \mathrm{MHz} \mathrm{CDCl}_{3}\right) \delta=171.1,159.0,155.4,129.0,86.2,53.8,51.7$, 28.7. IR $\left(\mathrm{cm}^{-1}\right) v=2990,2948,2829,1750,1696,1646,1443,1328$, 1204. HRMS (ESI): $\mathrm{m} / \mathrm{z}$ Calculated. For $\mathrm{C}_{8} \mathrm{H}_{12} \mathrm{NO}_{3}: 170.0817$, found: 170.0813 .

(29) Mal, D.; Pahari, P.; Senapati, B. K. Tetrahedron Lett. 2005, 46, 2097 2100.

(30) Takagi, R.; Nishi, T. Org. Biomol. Chem. 2015, 13, 11039-45.

(31) Harry, N. A.; Saranya, S.; Krishnan, K. K.; Anilkumar, G. Asian J. Org. Chem. 2017, 6, 945-966.

(32) Yang, C. S.; Liao, C. C. Org. Lett. 2007, 9, 4809-12. 